\title{
¿QUÉ PASA CON LA ENSEÑANZA DEL ALEMÁN EN LOS PAISES DEL ESTE (Y EN ANDALUCÍA)?
}

EI presente artículo se ta sobre el papel de las lenguas extranjeras en general, del alemán en particular, en los sistemas educativos de siete paises del este de Europa. Los entrevistados han sido profesores de alemán de dichos paises que conoci en un curso que realicé este verano en Viena, dirigido a profesores de alemán y organizado por el Ministerio de Cultura y Educación austriaco (Bundesministerium für Unterricht und Kunst), y en las opiniones que sobre el mismo tema, aunque refiriéndose a nuestro sistema educativo, manifestaron compañeros de la enseñanza de idiomas que trabajan en la aplicación de la LOGSE en Andalucía.

Por lo tanto no pretende ser un articulo ni exhaustivo ni científico, sino la exposición de una realidad, la importancia de las lenguas extranjeras, sobre todo de la alemana, en paises que están viviendo un periodo dificil de su historia, donde se están produciendo cambios políticos, sociales y económicos importantes, y en los que, a pesar de ello, la educación no se olvida, conscientes de su relevancia dentro del pro
"La posibilidad de comunicarse en una lengua extranjera constituye una necesidad en la sociedad actual. Es una necesidad acuciante en el marco de la unidad europea, de la circulación de profesionales y trabajadores entre los países de la Comunidad Europea, pero también de los viajes al extranjero, de los intercambios culturales y de la comunicación de noticias y conocimientos. Existe, por eso, una gran demanda social para que la educación obligatoria proporcione, a los alumnos una competencia comunicativa en alguna lengua extranjera."

(BOE Nr.152, 26-07-91) grama de reformas, de incitar al lector andaluz, que también trabaja o se preocupa por el papel de los idiomas extranjeros, del alemán en concreto, en el nuevo sistema educativo, a plantearse qué es lo que pasa con los idiomas en este pais, cómo están solucionando las instituciones educativas las deficiencias existentes - en cuanto a conocimiento de idiomas extranjeros se refiere - en los jóvenes que acaban su formación secundaria, y a reflexionar sobre cómo se están tratando los idiomas extranjeros en el nuevo sistema educativo.

Los resultados de la entrevista que realicé a siete profesores de Rusia, Bosnia, República Checa, Hungria, Croacia, Eslovaquia y Polonia son los siguientes:

Todos ellos afirman tener en la educación primaria una lengua extranjera obligatoria a elegir entre inglés y alemán, tambièn se oferta francés y ruso en algunos países como en Polo. nia, aunque aclaran que el ruso está en recesión. En algunas partes de Rusia como la República soviética de Yakutsk incluso japonés y chino. 
A la edad aproximadamente de 11 años se comienza con la primera lengua extranjera, oscilando entre los 8 años de Hungría y los 11 de Bosnia. En el Bachiller o enseñanza secundaria se amplia la oferta incluyendo idiomas de la Europa mediterránea como el italiano y el español, además del francés en la República Checa, Hungria, Croacia y Eslovaquia. Latín se oferta también en Hungria y Polonia. Todos los paises representados en la encuesta tienen dos idiomas extranjeros obligatorios en esta segunda etapa, normalmente alemán e inglés, y un tercer idioma optativo, elegible entre los anteriormente nombrados. La primera lengua extranjera suele ser el inglés y la segunda el alemán, pero en algunos centros, dependiendo del director de los mismos y la demanda de los alumnos, se invierte el orden.

A la pregunta de qué papel juegan las lenguas extranjeras en su sistema educativo, la respuesta fue unánime, muy importante, idiomas extranjeros es sinónimo de apertura al exterior, conocer otros mundos, otras culturas y gentes, y amplía el horizonte profesional, el este quiere contar con el turismo y la inversión económica occidental.

Más información
sobre los cursos
para profesores DaF
del Ministerio de
Educación Austriaco
en el "Tablón" de
esta revista.

de Berlin era el símbolo de la división del mundo, ha seguido con la caida del muro, y sigue siéndolo ahora con su papel de promotor de la unidad européa, con Berlín, sin muro, unificando en sus calles este y oeste, sur y norte. Los paises del antiguo Este parecen haber comprendido la importancia del alemán dentro del contexto europeo, de las posibilidades de integración dentro del sistema económico capitalista que los paises de habla alemana le ofrecen, naturalmente por intereses económicos pro pios, y esto se manifiesta en la importancia del alemán dentro de sus sistemas educativos.

Andalucia sin embargo, según las opiniones de mis compañeros de idiomas de secundaria, que también comparto, parece haberse quedado anquilosada en una oferta educativa ya exis. tente. Las Instituciones oficiales, conscientes del papel de cenicienta que hasta ahora han desempeñado los idiomas extranjeros en el sistema educativo, han intentado subsanar las posibles deficiencias en la Reforma del mismo. Sin embargo, aunque frases como la cita que aparece al principio de este articulo suenan muy bien, la realidad es distinta, y la Cenicienta parece que no quiere 0

Los países de habla alemana por su proximidad geográfica y por su historia, a veces dolorosamente común, han desempeñado siempre un papel relevante en los paises del Este. Ahora parece que quieren recuperarlo; una forma de hacerlo, probablemente la más duradera, es mediante la difusión de su lengua y cultura, ofreciéndose como mediadores entre dos mundos, crecidos alrededor de dos sistemas politica, económica y socialmente distintos, comunismo y capitalismo, que ahora se quieren reconciliar, naturalmente presentándose como lo que son, el coloso capitalista intentando recuperar al hermano comunista perdido. Siempre lo he dicho, la historia del siglo XX ha girado y gira entorno a Alemania, aunque sea para traer desgracias, pero el epicentro histórico estuvo alli, con las dos guerras mundiales, siguió con la guerra fria, donde el muro puede convertirse en princesa. Es verdad que la LOGSE prescribe dos idiomas extranjeros en la enseñanza secundaria mientras en el sistema educativo anterior sólo habia uno; pero la oferta no se ha ampliado: si antes se elegia entre inglés o francés, ahora en la mayoría de los centros, y salvo raras excepciones como algunos institutos que ofrecen alemán o italiano, los dos idiomas obligatorios son inglés y francés. Los germanistas, que esperábamos que con la Reforma el alemán entraría a formar parte del curriculum de secundaria, nos hemos quedado esperando. Todos sabemos que no sólo en la antigua Europa del Este, sino también en la del Oeste aprender alemán se ha convertido, a partir de la caída del muro de Berlín, en moda. Sin embargo Andalucia, posiblemente por ahorrar dinero en una operación cuyos resultados son a largo plazo y no a 
corto, parece no querer subirse al tren de la moda, en cuanto a enseñanza de idiomas se refiere, y prefiere quedarse en la estación esperando a que Europa venga a recogerla hablando incluso en castellano; claro, si el tren no pasa de largo.

¿Qué ha pasado con esa variedad de idiomas extranjeros que nos prometían? ¿Cómo se refleja esa apertura a Europa, esa participacion en la Europa comunitaria, si ni siquiera tenemos opción a aprender sus lenguas? ¿Qué se está haciendo para mentalizar al alumnado, y a la sociedad en general de la importancia del aprendizaje de lenguas extranjera? ¿Cómo nos hablan los boletines oficiales de su importancia y luego, en la práctica, no hacen nada más que mover o remover lo ya existente? ¿Cómo es que los países del Este, con todos los problemas que tienen que afrontar en este momento de su historia tratan mejor la educación, en este caso enseñanza de idiomas, que un país como España que ya tiene a sus espaldas una trayectoria democrática y aperturista? ¿Qué pasa con nuestros politicos? ¿Por qué se descuida la educación y dentro de ella los idiomas extranjeros? ¿Por qué no se le otorgan un papel similar al que tienen en los demás paises europeos?

No podemos quedarnos de brazos cruzados esperando que aparezca un buen día un hada madrina que con su varita mágica convierta a nuestros hijos en ciudadanos del futuro. Para que nuestros jóvenes puedan participar en la historia europea la enseñanza de idiomas juega un papel básico. La enseñanza pública tiene que ofertar idiomas extranjeros, y no sólo el inglés y el francés, como ha sido y sigue siendo, sino más idiomas européos; no puede olvidar el alemán, ni el portugués, ni el italiano. Que no haya que pagar academias o colegios privados para subsanar los defectos del sistema. Que no sólo sean los hijos de los acaudalados ciudadanos los que tengan acceso al aprendizaje de idiomas dentro de su plan de estudios.

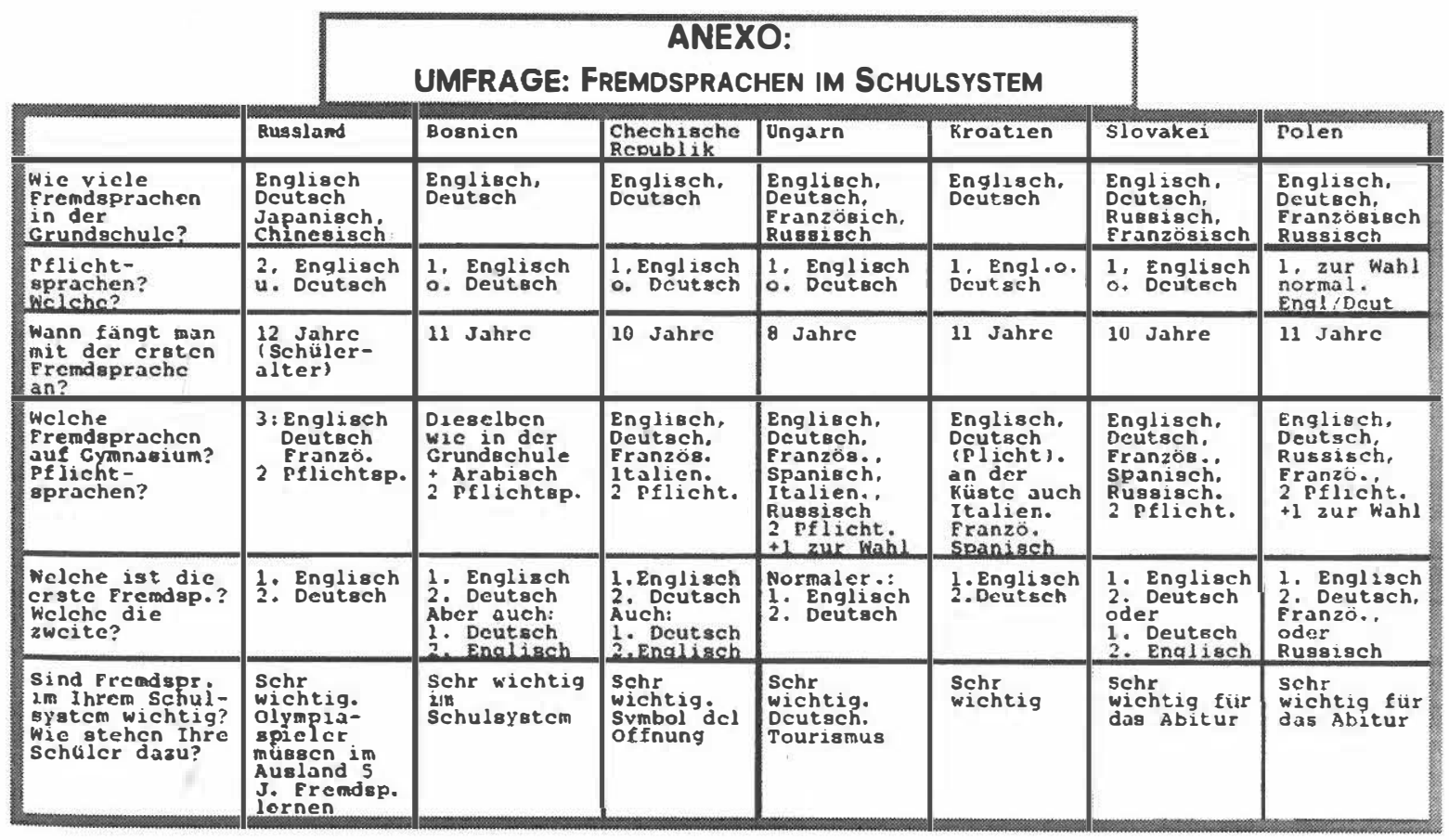

